\title{
Reported incidence of injuries caused by street glass among urban children in Philadelphia
}

\author{
Martin A Makary
}

\begin{abstract}
Objectives-First, to assess the incidence and cause of lacerations sustained by urban children from walking outdoors as well as to identify possible means of prevention. Second, to identify the type of health care sought after injury and to measure the extent of glass litter on the streets.

Setting-Children (18 years of age or younger) in the Ludlow community of Philadelphia.

Methods-A retrospective analysis of lacerations sustained while walking outdoors. A personal survey was conducted with 241 children on a door to door basis. Glass litter was measured by visual inspection of individual streets.

Results-Of 241 children, 83 (34\%) had been cut at least once while walking outdoors. Of the 83,62 were not wearing footwear at the time of injury. The majority of lacerations $(86 \%)$ were caused by broken glass. Thirty nine of the 83 children received professional medical care for the laceration. Broken glass was estimated to be present on $30 \%$ of the outdoor walking area.

Conclusions-Broken glass is a significant health problem on littered urban streets. Preventive measures such as street cleaning, footwear education, and glass recycling incentives are needed to address this public health hazard.

(Injury Prevention 1998;4:148-149)
\end{abstract}

Harvard School of

Public Health,

Harvard University,

Boston,

Massachusetts, and

Jefferson Medical

College, Thomas

Jefferson University,

Philadelphia,

Pennsylvania, USA

Correspondence to:

Martin A Makary,

$\mathrm{MD}, \mathrm{MPH}$, Department of

Surgery, Georgetown

University Hospital, 3800

Reservoir Road NW,

Washington, DC 20007,

USA (e-mail:

MMakary@hsph.harvard.edu).
Keywords: glass; urban children; cuts; lacerations

Lacerations rank as the most common pediatric injury that requires a physician evaluation. ${ }^{1-5}$ Glass is a frequent cause of wounds in patients who present to an emergency department. Armstrong and Molyneux observed that $5 \%$ of all injuries at their hospital in Liverpool, England, were caused by glass and that most glass related injuries occurred on the street. ${ }^{6}$ Both in England and the US, broken bottle glass has been reported to be the leading cause of lacerations, accounting for $15-27 \%$ of all lacerations seen in an urban emergency department. ${ }^{16}$ However, while many studies have analyzed laceration injuries using emergency department data, ${ }^{16-11}$ little is known about the out-of-hospital incidence or cause of lacerations in urban communities.

Lacerations due to glass can result in several health problems. Fragments of glass in a wound may lead to persistent pain, delayed healing, increased scarring, neuropraxis, and infection. ${ }^{12-16}$ In a prospective study of 415 children with cleaned and sutured lacerations in the lower extremities, $8.5 \%$ developed an infection. ${ }^{17}$ In addition, foreign body retention is more common when the wound is caused by stepping on glass as opposed to falling on glass, putting one's hand through glass, or being struck by glass. ${ }^{7}$ Glass injuries are special because the clinical assessment of the presence of a foreign body is difficult, ${ }^{18}$ and often insufficient to exclude the presence of retained glass. ${ }^{751920}$

This study was prompted by physicians and medical students, who during an urban immunization project, observed a surprisingly high prevalence of children playing without footwear in streets. The purpose of this study was to analyze the extent to which littered urban streets pose laceration dangers and to identify possible areas of prevention. A retrospective investigation analyzed the incidence and cause of lacerations sustained from walking outdoors, with particular attention to the circumstances surrounding injury (that is footwear, tetanus immunization status, and care given after injury) and the extent of glass litter on urban streets.

\section{Methods}

PATIENT POPULATION

The study included 241 children (18 years of age or younger) who were visited at their homes; 25\% were African American and 74\% were Latino. Home visitation was conducted by immunization teams working from two mobile van sites which covered a central urban area in Philadelphia.

\section{DATA COLLECTION}

Data collection was conducted as part of a Summer Medical Institute Child Immunization Program. Children less than 18 years of age were asked if they were ever cut from walking around outside and if so, what were the circumstances (see table 1). The information was 
Table 1 Survey questions

Were you ever cut from walking around outside?

How old were you when you were cut?

Where on your body were you cut?

Were you barefoot when you were cut?

What did you cut yourself on?

Was your tetanus immunization up-to-date at the time of the cut?

What care was given to the cut?

Where did you seek care?

confirmed by the parent (usually the mother). To assess the extent of broken glass litter on the streets, each street block visited was specifically inspected. The per cent of the sidewalk and road area with dangerous broken glass was measured by estimating the per cent of 3 square foot areas with visible glass per block. The walking area was considered to be the entire street block, including the roadway as well as the sidewalk. In cases where homes were located along a major roadway, the roadway was not considered to be a walking area. An average of all surveyed blocks was calculated.

\section{Results}

Of 241 children, 83 (34\%) had been cut at least once in their life while walking outdoors. Eight children $(10 \%)$ had been cut two or more times. The mean (SD) age of a child that had been cut was 8.9 (4.3) years. Most lacerations $(81 \%)$ were caused by broken glass, $6 \%$ by nails, and the remainder by a variety of other agents (that is rocks, cement). A total of $76 \%$ of the children cut their foot and another $13 \%$ elsewhere on the leg. Sixty two (75\%) children were not wearing footwear and $16 \%$ were not up-to-date with tetanus immunizations at the time of injury $(30 \%$ did not know their immunization history and immunization records were not available). After the laceration had occurred, $24 \%$ received a tetanus immunization, and $29 \%$ required sutures. Altogether $35 \%$ received professional care at a hospital or health center for the injury. Fifty seven urban street blocks were surveyed for glass litter as described in the Methods section. Thirty per cent of the walking area was assessed to be dangerous because of broken glass.

\section{Discussion}

Streets serve as a playground for many urban children. This study indicates the extensive amount of broken glass on the streets of one poor urban neighborhood. When children are lacerated by broken glass, lack of proper immunization exacerbates the problem. Many parents commented that virtually all children in this neighborhood probably had been injured by glass at some point in their lives. Further study is needed to assess the generalizability of the Philadelphia area studied to other urban areas.

\section{Implications for prevention}

In Massachusetts, broken glass recycling legislation led to a $60 \%$ reduction in glass related lacerations in children in the course of one year. ${ }^{8}$ Such successful legislation is based on the model of providing a small financial incentive for the return of empty containers. The permanence of non-degradable trash, such as metal and glass, compounds the problem from year to year, calling for immediate preventive health action. Education by primary care providers, social workers, or home health providers may also help prevent injuries and increase public awareness. Preventive health efforts should be directed foremost to cleaning urban streets, and to encouraging proper footwear. Ultimately, strong action is necessary to address broken glass as a health hazard. Glass littered urban streets need to be treated as an important public health problem.

The author wishes to thank Bill Pearson and the Christian students of the Summer Medical Institute for their help in data collection and for their compassion on the residents of North Philadelphia. The author also thanks Maria Segui-Gomez and their guidance and comments in preparing the manuscript.

1 Baker MD, Selbst SM, Lanuti M. Lacerations in urban children. Am $\mathcal{F}$ Dis Child 1990;144:87-92.

2 Chenoweth A. Health problems of infants and children. In: Wallace H, Gold E, Liss E, eds. Maternal and child health practices. Springfield, IL: Charles C Thomas, 1973: 651-66.

3 Rivara F, Bergman AB, Logerfo JP, et al. Epidemiology of childhood injuries, II: sex differences in injury rates. $A m \mathcal{F}$ Dis Child 1982;136:502-6.

4 Manheimer D, Dewey J, Mellinger GD, et al. Fifty thousand child-years of accidental injuries. Public Health Rep 1966;81:519-33.

5 Izant R, Hubay C. Annual injury of 15,000,000 children: a limited study of childhood accidental injury and death. $\mathcal{f}$ Trauma 1966;6:65-74.

6 Armstrong AM, Molyneux E. Glass injuries to children. $B M F$ 1992;304:360.

7 Montano JB, Steele MT, Watson WA. Foreign body retention in glass-caused wounds. Ann Emerg Med 1992;21: $76-9$.

8 Baker MD, Lanuti M. The management and outcome of lacerations in urban children. Ann Emerg Med 1990;19: 1001-5.

9 Baker MD, Moore SE, Wise PH. The impact of "bottle bill" legislation on the Incidence of Lacerations in Childhood. Am 7 Public Health 1986;76:1243-4.

10 Bell D. Two hundred glass injuries. Arch Dis Child 1984;59: 672-3.

11 Ousby J, Wilson DH. 1086 Consecutive injuries caused by glass. Injury 1980;13:427-30.

12 Avner JR, Baker MD. Lacerations involving glass. The role of routine roentgenograms. Am f Dis Child 1992;146: $600-2$.

13 Courter BJ. Radiographic screening for glass foreign bodies - what does a "negative" foreign body series really mean? Ann Emerg Med 1990;19:997-1000.

14 Barnett RC. Soft tissue foreign body removal. In: Roberts $\mathrm{JR}$, Hedges JR, eds. Clinical procedures in emergency medicine. Philadelphia: WB Saunders, 1985:537-47.

15 Anderson M. Diagnosis and treatment of retained foreign bodies in the hand. Am $\mathcal{F}$ Surg 1982;144:63-7.

16 American College of Surgeons Committee on Control of Surgical Infections. Control of infection in surgical patients. 2nd Ed. Philadelphia: JB Lippincott, 1984:127-8.

17 Rosenburg N, DeBaker K. Incidence of infection in pediatric patients with laceration. Pediatr Emerg Care 1987;3:23941 .

18 Tandberg D. Glass in the hand and foot. $7 A M A 1982 ; 248$ : 1872-4.

19 Gron P, Andersen K, Vraa A. Detection of glass foreign bodies by radiography. Injury 1986;17:404-6.

20 Browett J, Fiddian N. Delayed median nerve injury due to retained glass fragments. $\mathcal{F}$ Bone foint Surg Am 1985;17: $1336-44$. 